ARBOR Ciencia, Pensamiento y Cultura

Vol. 188 - 755 mayo-junio (2012) 457-473 ISSN: 0210-1963 doi: 10.3989/arbor.2012.755n3001

\section{FRONTERAS ABIERTAS, DERECHOS HUMANOS Y JUSTICIA GLOBAL*}

\author{
Juan Carlos Velasco \\ Instituto de Filosofía del CSIC (Madrid)
}

\section{OPEN BORDERS, HUMAN RIGHTS AND GLOBAL JUSTICE}

\begin{abstract}
A world with "open borders", which does not mean a "world without borders", would provide the most appropriate institutional framework for the recognition of human rights and the implementation of distributive justice on a global scale. This is the thesis we want to substantiate in this article. Such still fictional horizon is compared with the actual state of affairs, characterized by the systematic impediment of free circulation of people. Against this background, and with the aim to face in a more comprehensive way the question of international migration, the necessity of adopting a cosmopolitan point of view is demonstrated. To keep in view such utopian option that nevertheless is not beyond the bounds of possibility results indispensable for a critique of the disturbing perspective that conceives of human mobility as a potential threat for the established order.
\end{abstract}

KEY WORDS: Free movement of persons; international migrations; right to migration; open borders; human rights; national sovereignty; cosmopolitanism; global justice; globalization; neoliberalism; utopia.

\begin{abstract}
RESUMEN: Un mundo con "fronteras abiertas", que no un "mundo sin fronteras", aporta el marco institucional más propicio para el respeto de los derechos humanos y la instauración de la justicia distributiva a nivel planetario. En este artículo se argumenta a favor de esta tesis. El horizonte propuesto se compara con el actual estado de cosas, caracterizado por la obstrucción sistemática de la libre circulación de personas. Ante este panorama, y con el fin de afrontar de manera más integral la cuestión de las migraciones internacionales, se señala la necesidad de adoptar una mirada cosmopolita. Mantener a la vista una opción situada más allá de lo realmente existente, que no de lo posible, resulta imprescindible para poder someter a una mirada crítica la inquietante perspectiva que nos presenta la movilidad humana como una potencial amenaza para el orden establecido.
\end{abstract}

PALABRAS CLAVE: Libre circulación de personas; migraciones internacionales; fronteras abiertas; derechos humanos; soberanía nacional; cosmopolitismo; justicia global; globalización; neoliberalismo; utopía.

\begin{abstract}
"Ahora debemos aprender a ser mutuamente invitados los unos de los otros en lo que queda de esta herida y superpoblada tierra. [...] Los árboles tienen raíces; los hombres y las mujeres, piernas. Y con ellas cruzan la barrera de la estulticia delimitada con alambradas, que son las fronteras; con ellas visitan y en ellas habitan entre el resto de la humanidad en calidad de invitados. [...] La intromisión puede ser nuestra llamada, un modo de sugerir a nuestros semejantes que todos los seres humanos deben vivir unos y otros como 'invitados de la vida'".
\end{abstract}

(Steiner 2011, 75-76)

En torno a la deseabilidad y viabilidad de un mundo con fronteras abiertas se mantiene, desde hace más de dos décadas, un amplio y animado debate académico que, como es habitual, ha dado lugar a una extensa bibliografía. El centro de la controversia no radica en la supresión de las fronteras políticas, sino más bien en el control o no de las fronteras para el paso de seres humanos, esto es, en el reconocimiento o no de la libre circulación de personas. Un artículo de Joseph Carens publicado en 1986 ("Aliens and citizens: the case for Open Borders"), que planteaba la cuestión de la justificabilidad ética de los criterios de admisión y selección de inmigrantes desde una perspectiva liberal, ejerció una labor pionera al lograr abrir una fructífera discusión. A partir de entonces, se han esgrimido una gran variedad de argumentos (morales, políticos, económicos, culturales, etc.) tanto en pro como en contra (cf. Wellman 2010). Por lo general, los argumentos aducidos a favor de la apertura de fronteras comparten posiciones de fondo que tienen un reconocible aire de familia liberal y cosmopolita. En particular, los cosmopolitas igualitaristas 
ven en las fronteras abiertas una forma de responder a las enormes desigualdades existentes entre países. A favor de esa posición confluyen también posiciones libertarias, que promueven las transaciones voluntarias entre las personas (tanto de los nativos como de los extranjeros) y perspectivas utilitaristas. En contra, es decir, a favor de mantener las fronteras cerradas, se arguye -desde posiciones más bien comunitaristas, aunque también desde un nacionalismo de corte liberal- el derecho de autodeterminación de las comunidades políticas, así como argumentos basados en la preservación de la cultura, la integridad de la identidad colectiva, el mantenimiento del nivel económico, la seguridad, el bienestar (en particular, el reparto de los beneficios asistenciales) e incluso el funcionamiento del sistema político. Unos y otros argumentos están implícitos en este artículo y, aunque no serán objeto de un análisis específico, servirán para perfilar una posición propia.

La libertad de circulación a lo largo y ancho del planeta es un derecho básico de todo ser humano. La carga de la prueba recae en quien preconiza suspenderlo o restringirlo. Este presupuesto constituye el punto de partida del presente artículo, de modo que se ahorrará espacio en la tarea de fundamentar dicho derecho en cuanto tal y se incidirá, más bien, en la de poner en evidencia la amplia difusión de prácticas destinadas a negarlo, a desdibujarlo o a cuestionar su contenido esencial. No obstante, un segundo objetivo de este escrito, y en absoluto lateral, consistirá en mostrar que el reconocimiento generalizado del ius migrandi como un derecho básico de las personas representa una forma de ordenar los actuales flujos migratorios preferible -tanto desde un enfoque normativo como desde una perspectiva meramente pragmática o funcional- a las habituales políticas encaminadas a intentar controlar 0 incluso bloquear las fronteras. Se abogará, en consecuencia, por un mundo en el que la apertura de fronteras sea la regla y no la excepción.

Esta posición de partida será convenientemente perfilada a lo largo del presente artículo. En primer lugar, se examina de una manera crítica la configuración asimétrica que desde el derecho internacional se ofrece del derecho a la libre circulación de las personas (1). A continuación, se destaca cómo la soberanía estatal representa un obstáculo estructural para el ejercicio de dicha libertad (2), de tal manera que, pese a los actuales procesos de globalización, las personas que desean migrar no sólo siguen topándose con las habituales fronteras políticas, sino incluso con nuevas barreras que lesionan gravemente sus derechos humanos más básicos (3). Ante este panorama, y con el fin de afrontar de manera más integral la cuestión de las fronteras y las migraciones internacionales, se señala la necesidad de adoptar una mirada cosmopolita $y$, más concretamente, una perspectiva de justicia global (4). Finalmente, se arguye la pertinencia de abrir un debate público sobre la apertura de fronteras y la conveniencia de formular propuestas innovadoras, incluso aunque pudieran ser consideradas utópicas (5).

\section{LA LIBRE CIRCULACIÓN DE PERSONAS EN EL DERECHO INTERNACIONAL}

Hablar del derecho a la libre circulación de las personas en el mundo de hoy es adentrarse en un campo minado de paradojas, por no decir de flagrantes contradicciones. De entrada, que el conjunto de la superficie del planeta que habitamos todos fuera accesible a cualquiera que pretenda y pueda desplazarse debería ser algo completamente normal. Al fin y al cabo, la Tierra entera es propiedad común de la humanidad (dicho sea esto con el permiso de las otras especies animales que habitan este planeta), una propiedad que cada generación recibe como herencia inmerecida.

La ocupación continuada de un determinado territorio por un grupo humano - un hecho histórico mil veces repetido, ya sea por medios pacíficos o de manera violenta- genera ciertos derechos de uso, que, sin embargo, no pueden negar ni desvirtuar el derecho más básico de todo individuo a relacionarse con los demás seres humanos ni tampoco cancelar la obligación de dar acogida a individuos procedentes de otros lugares ${ }^{1}$. De este tipo de planteamientos -tan suscintamente esbozados- se derivaría como colorario el denominado ius migrandi: el derecho de toda persona no sólo a desplazarse a lo largo del planeta, sino también a mudar su lugar de asentamiento e instalarse en donde juzgue conveniente.

La posibilidad de decidir dónde vivir es un aspecto fundamental de la libertad humana. Esta aseveración resulta completamente evidente cuando el destinatario es uno mismo. Nadie se negaría este elemental derecho a sí mis$\mathrm{mo}^{2}$. Sin embargo, no se procede siempre de la misma 
manera cuando se trata de aplicarlo a los demás. Entonces valen mil distingos. Un despropósito que a lo largo de los últimos tiempos no ha hecho sino agravarse, de modo que la distancia entre la teoría y la práctica acaba resultando abismal. No hay más que remitirse a las pruebas. La libre circulación de las personas, así como la libertad de residencia, es un derecho humano básico $y$, sin embargo, la forma concreta en que está regulado adolece de un grado tal de asimetría que raya con el absurdo. Un rasgo visible incluso en el texto normativo más significativo sobre los derechos humanos, la Declaración Universal de 1948 (DHUD), cuyo artículo 13 proclama: "1. Toda persona tiene derecho a circular libremente y a elegir su residencia en el territorio de un Estado. 2. Toda persona tiene derecho a salir de cualquier país, incluso del propio, y a regresar a su país".

Dicho crudamente y sin rodeos: "La emigración es un derecho humano, mientras que la inmigración no lo es" (Heller 1992). Eso es lo que se desprende de la legislación internacional vigente sobre la materia, inspirada en el citado artículo de la DUDH. En ella se reconoce a toda persona el derecho de abandonar el Estado del que sea nacional, así como el de retornar a él, pero se guarda, empero, un estrepitoso silencio acerca de la correlativa obligación de los otros Estados de aceptar su entrada en el territorio de su propia jurisdicción. Es cierto, y no se puede negar, que en su momento normas de tal tenor representaron un avance frente a las restricciones feudales a las que estaban sometidos los siervos, que, en el mejor de los casos, estaban obligados a pagar un peaje para poder salir. Hasta bien entrada la edad contemporánea, la población era considerada por la mayoría de los gobiernos como uno de sus bienes básicos y era vinculada a la prosperidad y al poder económico y militar del pais, por lo que se mostraban sumamente renuentes a permitir la salida de sus súbditos. La privación de la condición de nacional y la confiscación de bienes eran penas habituales si se emigraba sin autorización oficial. Las regulaciones derivadas de la DUDH representan, sin duda, una sensible mejora también frente a los severos controles de salida que hasta hace poco mantenían países de corte totalitario, como los del antiguo bloque soviético, prácticas que, por cierto, aún subsisten en Cuba y Corea del Norte. Y suponen asimismo un avance frente a la práctica del ostracismo, típico recurso punitivo de los regímenes autoritarios para deshacerse de la disidencia interna.
Conforme a las mencionadas normas internacionales, existe, pues, un derecho de salida del propio país, pero, en cambio, nada se dice acerca del de entrada en otro, salvo en los casos en que se huya de persecución, ya sea política, étnica o religiosa, en cuyo caso es de aplicación el derecho de asilo. Es éste, por cierto, un derecho positivamente tutelado, pero administrado con frecuencia de manera cicatera por muchos países, incluso democráticos, que han firmado convenios -empezando por el artículo 14 de la DUDH y siguiendo con la Convención y el Protocolo sobre el Estatuto de los Refugiados (1951/1967)- que les vinculan jurídicamente.

La legislación internacional afirma, es verdad, el derecho a emigrar, pero ignora su contrapartida lógica, el derecho a inmigrar, con lo cual se acaba conculcando el primero de esos derechos. Falla, pues, la clave de bóveda de la construcción: el derecho a inmigrar no está configurado, y menos aún codificado, de manera vinculante para los potenciales Estados receptores. Para sus potenciales destinatarios no es más que un derecho condicionado. Se registra, por tanto, un notable desajuste entre el reconocimiento irrestricto de la libertad emigratoria y el sometimiento fáctico del derecho a inmigrar a la decisión soberana de los países receptores. No obstante, en estricta lógica jurídica, el deber de acogida está ya implícito, pues cuando se reconoce un derecho se adquiere también la obligación de no impedir su realización ${ }^{3}$. Pero mientras la lógica y la recta interpretación discurren por sus cauces, los Estados se desatienden de las obligaciones contraídas. En medio de su viaje, el migrante permanece entonces atrapado de facto en una zona de paso, en una difusa zona normativa donde sus derechos quedan como mínimo en suspenso.

Por lo demás, la peregrina idea de que a un individuo se le puede otorgar el derecho a salir de su país sin reconocerle al mismo tiempo el derecho a entrar en otro únicamente sería pensable si introducimos en la argumentación un supuesto que podría resultar plausible en momentos pretéritos de la historia: la presunta existencia de tierras que no pertenecen a nadie. A esta creencia, cargada de un evidente componente ideológico, se hacía referencia mediante la noción de terra nullius, con la que, por ejemplo, durante la era de los colonialismos se aludía a aquellos territorios no ocupados o que no formaban parte de ningún Estado reconocido por la comunidad internacional ${ }^{4}$. Allí, por supuesto, sí que tendría derecho a ir, e incluso a establecerse, todo 
aquel que ejerce el derecho a salir y se encuentra con que ningún Estado le acoge. Sin embargo, esa opción, en el mundo de hoy, no es más que una absurda entelequia: en este finito planeta no existe ningún lugar adonde ir que no sea territorio soberano de alguna entidad política.

La configuración asimétrica del derecho a migrar que, como se ha señalado es la que está vigente, es, sin duda, difícilmente sostenible en términos normativos (cf. Benhabib 2006, 276-282). Son infinidad las preguntas que pueden llegar a plantearse: ¿Cómo puede argumentarse, por ejemplo, que negar a una persona la entrada en un país -sin que medien impedimientos objetivos como pueden ser la protección de la salud pública u otros similares- no representa una violación palmaria de los derechos humanos? ¿Existe alguna razón compatible con los derechos humanos que autorice negar el acceso a alguien que huye de la miseria material o que no puede ni desea seguir viviendo bajo un gobierno tiránico? ¿Puede utilizar un Estado la fuerza contra individuos que penetran en el territorio de su jurisdicción sin agredir a nadie ni atacar ninguna propiedad pública o privada? ¿Tiene derecho a deportarlos y penalizar incluso a quienes les ofrezcan hospitalidad? ¿Tienen potestad los Estados para constreñir la interacción voluntaria entre personas?

\section{LIBERTAD DE CIRCULACIÓN VS. SOBERANÍA DE LOS ESTADOS}

Según la costumbre y el derecho internacional, el acto de migrar no constituye un crimen, ni siquiera un delito, sino más bien un derecho. En consecuencia, si los Estados se tomaran en serio esta libertad, deberían abstenerse de desplegar cualquier tipo de política y legislación orientada a criminalizar la inmigración no expresamente autorizada. Tenemos constancia, sin embargo, de que se hace justo lo contrario. Como ejemplo de caso extremo de ese tipo de práctica puede presentarse la polémica ley SB1070, promulgada por el Estado de Arizona en 2010 (aunque al poco tiempo su aplicación fuera suspendida por un tribunal federal), que legaliza la detención arbitraria de personas "sospechosas" de ser inmigrantes irregulares (illegal alien) y que convierte en autor de un crimen estatal de entrada ilícita a cualquier persona que no sea ciudadano y acceda sin el pertinente permiso en el territorio de los Estados
Unidos (cf. Celador 2011). En la legislación penal italiana, por señalar otro caso, se ha introducido recientemente el "delito de inmigración clandestina". De un simple plumazo fueron criminalizadas miles de personas en situación administrativa irregular. Para ilustrar lo dicho, también podría valer la abundante legislación existente en numerosos Estados europeos dirigida a perseguir a los inmigrantes indocumentados y que faculta a las autoridades a recluirlos en centros de internamiento paracarcelarios o a expulsarlos del país con más o menos miramientos. En la Unión Europea se detecta, en general, una tendencia a la desjudicialización de los procesos de detención y expatriación de los sin papeles. Todas estas medidas ejemplifican con claridad el uso cotidiano del poder coercitivo estatal en la represión de la inmigración irregular ${ }^{5}$. Aunque estos métodos no son nuevos, su empleo se ha intensificado últimamente, pues en su auxilio se ha presentado, como coartada perfecta, la extendida obsesión securitaria que, a partir del 11-S, domina el espacio y el discurso público (cf. Arango 2011). Especialmente en Estados Unidos, se ha propagado con éxito la imagen de un país sitiado y amenazado por enemigos internos y externos. Expresión representativa de esa retórica de la seguridad nacional son estas palabras de un ex-presidente de la Cámara de los Representantes de aquella nación: "Ningún país serio en la era del terror puede permitirse el lujo de tener abiertas las fronteras a millones de extranjeros ilegales que cruzan a su antojo" (Gingrich 2010, 78).

En realidad, para cerrar las fronteras al paso de las personas no era imprescindible presentar a los migrantes como potenciales terroristas. Se trata, más bien, de una excusa sobrevenida, pues las barreras físicas estaban erigidas desde mucho antes, desde el mismo momento en el que el control del tránsito de migrantes fue equiparado con la lucha contra el narcotráfico, la trata de blancas y el contrabando en general. La materia se abordaba, pues, desde una lógica policial, cuando no estrictamente militar. Aunque a partir del derribo de las Torres Gemelas se potenciaron los muros, ahí estaban ya, dotados de alumbrado de alta intensidad y cámaras, y equipados con detectores térmicos y de movimiento. Erigidos en un intento de frenar la inmigración ilegal, cubrian y siguen cubriendo una parte considerable de los 3.152 kilómetros de la frontera entre Estados Unidos y México, la más larga y dramática línea de encuentro entre un país rico y otro pobre (cf. Anguiano 2010). Tales barreras no impiden, sin embargo, que ambos 
países mantengan "el nexo migratorio bilateral más importante en el mundo" (Castles y Miller 2004, 343).

Por otro lado, hace ya también tiempo que se tendieron verjas de alambradas, de hasta seis metros de altura, para resguardar el perímetro terrestre de las ciudades norteafricanas de Ceuta y Melilla e impedir el ingreso en territorio español del tránsito migratorio procedente de Marruecos. También la Unión Europea, y no sólo en esos dos lugares, ha hecho del cierre de fronteras su "doctrina migratoria" (cf. Wihtol de Wenden 2000, 33 y 41) y de la lucha contra la inmigración ilegal, su estrategia para implementarla. La asi llamada Fortaleza Europa es mucho más que una socorrida metáfora para empleo periodístico: impulsada por un no siempre confesado chovinismo del bienestar ${ }^{6}$, es una realidad tangible planeada con la finalidad de intentar contener el oleaje de la indigencia planetaria 7 . Además de los importantes reparos normativos (jurídicos, políticos y morales) que pueden formularse ante tales actuaciones y medidas, está por ver si el mantenimiento simultáneo de un espacio interior abierto y de un espacio exterior cerrado como el que propugna la Unión Europea es realmente practicable en el actual contexto geopolítico y, más aún, en el previsible a medio y largo plazo.

La construcción de muros y la militarización de las fronteras es una práctica cada vez más habitual que, sin embargo, no detiene el tránsito internacional de personas. No se conoce frontera alguna que sea infranqueable. Ni la policía fronteriza, ni el ejército, ni la armada, ni los vuelos de observación, ni las cámaras de televisión, ni los sofisticados sistemas de sensores alcanzan la eficacia requerida en la consecución del objetivo perseguido. Lo mismo cabe decir de la intensificación y del refinamiento de las medidas de control de los aeropuertos, del desplazamiento preventivo de esos controles a los paises de origen o de la generalización de la exigencia de dotarse de pasaportes biométricos. Ninguno de estos procedimientos, en los que no se escatima esfuerzo, sirve para impedir realmente que las personas entren en un país y menos aún para detener a quienes azuzados por la desesperación quieren salir de su propio país. Valen únicamente para agudizar el ingenio a la hora de burlarlas, agravar el riesgo físico y encarecer el peaje debido a los traficantes.

A la vista está, sin embargo, que estos métodos se han ido sofisticando con el transcurso de los años. De momento,

doi: 10.3989/arbor.2012.755n3001 el último grito sería la denominada extraterritorialización o externalización del control fronterizo, de la que la Unión Europea y, en particular, España se han convertido en auténticos especialistas (cf. W.AA. 2008). Se trata de encomendar a países de tránsito la tarea de cerrar las vías de comunicación entre países emisores y receptores. Como contrapartida a su labor, estos países tapones reciben ayudas al desarrollo o se entablan con ellos relaciones comerciales privilegiadas. Como se diría en el lenguaje de la calle, se paga a terceros países para que ejerzan de aduaneros externos y ejecuten el ingrato cometido de quitarse el muerto de encima. Esta táctica se completa con la firma de acuerdos bilaterales de readmisión y/o repatriación con países que a menudo poseen un historia poco presentable en materia de derechos humanos. Estas políticas de externalización no son sino un nuevo caso de la ubicuidad de las fronteras (cf. Balibar 2003). La lógica del cierre de fronteras sigue siendo la misma y esta lógica genera efectos perversos: por un lado, el exceso de control y vigilancia conduce al aumento de la clandestinidad, con todo lo que implica de degeneración del Estado de derecho y la democracia; y, por otro, se da carta de legitimidad a la xenofobia que, a la postre, puede devenir en prácticas discriminatorias ${ }^{8}$. De este modo, el recorte sustancial de derechos está servido y con ello también el aumento de la vulnerabilidad de los inmigrantes frente a los abusos, la explotación en el mundo laboral y la postergación en el acceso a servicios y prestaciones sociales.

Aunque ahora pueda parecer extraño, las migraciones pacíficas no siempre fueron consideradas una amenaza. Durante largos períodos de la historia fueron bienvenidas e incluso incentivadas ${ }^{9}$. ¿Cómo es posible que los controles de las fronteras se hayan vuelto especialmente restrictivos y que, sobre cualquier otra consideración, imperen los temores ante los flujos migratorios? No hay una respuesta clara, pero no cabe duda de que la cuestión de la movilidad humana "ha eclosionado y se ha instalado en el seno de las sociedades en términos de conflicto" (Mármora 2003, 40) La cuestión es ahora percibida de modo bastante semejante a como antaño lo fue el proletariado: "un fantasma recorre el mundo y es el fantasma de la migración" (Hardt y Negri 2002, 202). Especialmente tras la finalización de la Guerra Fría, los procesos migratorios empezaron a figurar entre las principales preocupaciones de la opinión pública y la contención de los flujos pasó a formar parte de la agenda política, un cambio nada insustancial que ha te-

ARBOR Vol. 188755 mayo-junio [2012] 457-473 ISSN: 0210-1963 
ñido de incomprensión e intolerancia el discurso cotidiano sobre el tema. $Y$ entre las consecuencias indeseables de esa deriva cabe reseñar la siguiente: se desdeña, cuando no se condena sin más, aquel planteamiento alternativo, mucho más positivo y no menos realista, que encara las migraciones como una oportunidad, por todo lo que encierran de potencial contribución al desarrollo humano, y como factor de creatividad y de dinamismo económico-social (cf. PNUD 2009).

El diseño de políticas migratorias restrictivas responde con frecuencia a una comprensión de los flujos migratorios como si obedecieran fundamentalmente a una dinámica unilateral procedente del exterior y no a una compleja red de relaciones multilaterales de carácter no sólo económico, sino también sociocultural. Se ignora aquella dimensión multilocal del fenómeno que le dota, con frecuencia, de un marcado sesgo transnacional (cf. Velasco 2009). La imposición de cláusulas de prioridad nacional a la hora de regular el acceso de trabajadores inmigrantes (cláusulas que prescriben, por ejemplo, que sólo cuando todos los nacionales dispongan de trabajo, o al menos no lo demanden, se tendrán en cuenta las solicitudes de los no nacionales) apuntan también en esa misma dirección: hacia la renacionalización del discurso político, no exenta de una cierta obsesión identitaria. La inmigración representa en este sentido un campo de prueba privilegiado para indagar los límites normativos del orden institucional centrado en el Estado-nación, de sus contradicciones y tensiones internas (cf. Sassen 2010, 368-369).

Desde la consolidación de los modernos Estados nacionales, el mero hecho de plantear la posibilidad de reconocer la libre circulación de personas $-y$, con ella, la paulatina configuración de un mundo con fronteras abiertas- suele ser considerado un desafío directo a una sacrosanta facultad atribuida tradicionalmente a dichas entidades soberanas: la de controlar sus fronteras territoriales y reservarse el derecho de admisión. No deja, sin embargo, de sorprender que la libre circulación de personas se conciba como un reto a la soberanía estatal justo cuando la primacía de los mercados se ha impuesto fáctica y discursivamente sobre los gobiernos legítimamente constituidos y su marcada lógica territorial.

La libertad de circulación y residencia se topa con la obstinación de los Estados contemporáneos, que porfian por reafirmar su soberanía. La noción aún imperante de soberanía estatal sigue pivotando sobre el control en exclusiva de un determinado territorio ${ }^{10}$. Como consecuencia, la espontaneidad de los flujos migratorios queda condicionada por los constantes, aunque pocas veces eficaces, empeños estatales tendentes a planificarlos, orientarlos y regularlos. De manera mucho más contundente que en tiempos anteriores, los protagonistas de tales movimientos chocan con la lógica de la ciudadanía, que no es precisamente una lógica dinámica y menos aún migrante, sino estática y residencial, anclada en el territorio. Tras la persistencia de las fronteras territoriales se encuentra una implacable lógica estatal empeñada en marcar los confines entre los de dentro y los de fuera, en separar a los seres humanos en ciudadanos y en extranjeros, "en sujetos de derechos y en extraños al derecho" (Galli 2010, 53). Una lógica excluyente, además de profundamente inhospitalaria (cf. Bello 2011). Las fronteras, por tanto, no son sólo las físicas que delimitan territorios, sino también aquellas otras normativas y simbólicas que excluyen a los inmigrantes de la esfera pública y de los recursos comunes. Cometido propio del Estado nacional sería, incluso más que la preservación de su territorio mediante el control de las fronteras externas, la demarcación de la comunidad política -de quiénes la integran y de quiénes no- mediante el establecimiento de fronteras internas, más sutiles, pero, llegado el momento, no menos determinantes (cf. Baggio 2010).

Con todo, podria aceptarse que toda comunidad política legítimamente constituida tiene el derecho a definir sus propios contornos y su composición interna $y$, por tanto, también a controlar la inmigración. La facultad para establecer las condiciones de inclusión y exclusión estaría precisamente en la raíz de la autodeterminación comunitaria (cf. Walzer 1993, 44-74). De ahí, sin embargo, no se sigue que tal derecho sea absoluto $y$, menos aún, que no puedan ser cuestionadas las formas concretas en que se implementa. En realidad, como sabemos, ningún derecho es absoluto y el sentido de la justicia incorporado en las instituciones y en la legislación de cada Estado supone, en cualquier caso, un límite irrebasable a su ejercicio: nuestro sentido de "la justicia", como nos recuerda Carens (2002, 25), "impone importantes constricciones morales sobre cómo ha de ejercerse tal control". En particular, los Estados deben respetar además sus obligaciones internacionales - pacta sunt servanda- y proteger los derechos humanos no sólo los de sus ciudadanos, sino los de todas las personas, sean migrantes, 
desplazados, refugiados o solicitantes de asilo. Sin embargo, en la mayoría de los casos, el deficiente grado de protección real de los derechos humanos de los migrantes mantiene una relación directa con la asunción de una noción fuerte de soberanía estatal por parte tanto de los poderes públicos como de la opinión pública, una categoría dogmática que no hace sino lastrar toda la acción política.

Con la expansiva lógica universalista de los derechos humanos -positivizados por medio de múltiples convenios internacionales y constitucionalizados, en muchos casos, en los ordenamientos internos- se pone precisamente en cuestión que la soberanía implique no sólo el derecho de un Estado a controlar sus fronteras, sino incluso la potestad para definir los procedimientos de admisión de extranjeros en su interior (cf. Benhabib 2006, 244-249). Si esto es así, entonces los controles habrán de ser la excepción y la regla, que las fronteras permanezcan habitualmente abiertas, salvo razones de fuerza mayor. 0 dicho en otros términos: "aunque los Estados puedan conservar sus límites territoriales, éstos no deben constituir obstáculos para la movilidad; y el derecho a vivir y trabajar dentro de un Estado no debe depender del lado de la frontera en que se haya nacido" (Kymlicka 2006, 37-38).

Pretender justificar normativamente que las fronteras -líneas de tinta trazadas en un mapa, por más que por ellas se hayan derramado con frecuencia ríos de sangre- puedan convertirse en legítimos obstáculos para la movilidad de las personas, supone un desafío difícil de superar para aquellas sociedades que proclaman los derechos humanos como fundamento de su ordenamiento interno. Tales sociedades se han autodesarmado dialécticamente $y_{1}$ por tanto, se han incapacitado para construir $y$, sobre todo, para defender públicamente argumentos de peso contra el alcance universal de esos derechos y poder legitimar la facticidad de las fronteras nacionales. Si operan así, como de hecho hacen, acaban instalándose en una permanente contradicción, que por habitual que sea, no deja de originar disfuncionales desajustes internos.

\section{LIBERTAD DE MOVIMIENTO Y GLOBALIZACIÓN FRONTERIZADA}

La gestión política de la cuestión migratoria tiene a veces el extraño efecto de conceder un cierto carácter nacio- nal -al menos simbólicamente- a la agenda política. En particular, las severas políticas de control de los flujos migratorios y vigilancia de las fronteras, aunque a veces no sean más que gestos vacíos de escasa operatividad en relación al fin perseguido, pero de negativas y palpables consecuencias para las personas afectadas, constituyen un socorrido recurso utilizado por muchos Estados para intentar convencer a sus ciudadanos de que aún conservan soberanía y poder decisorio, cuando en realidad los están perdiendo a marchas forzadas. Los mercados, que no conocen fronteras, son los que definen el marco laboral, social y económico y no al revés, que sería lo propio desde una lógica democrática. Las lógicas del Estado y del capital se contraponen y en este duelo, según parece, la primera lleva las de perder. En el tratamiento de las cuestiones migratorias se vuelve, sin embargo, a aquella concepción política tradicional, según la cual se considera incumbencia privativa e irrenunciable de la soberanía estatal la misión de definir quiénes pertenecen al cuerpo político. En realidad, se entiende mucho mejor el sentido de los actuales procesos de globalización si se los considera como acelerados procesos de desnacionalización que avanzan en la configuración de un escenario mundial unificado. Por ello, en un mundo crecientemente globalizado, esta tendencia renacionalizadora no puede ser enjuiciada sino como algo extemporáneo, y más aún si se tiene en cuenta que el sistema migratorio internacional está cada vez más mundializado y sus efectos se dejan sentir en cualquier región del planeta por muy remota que parezca.

En un mundo en el que la producción de bienes, el comercio y las finanzas, pero también las comunicaciones, los transportes y la información se suceden en un escenario unificado, esto es, en un único espacio mundial en donde se han derribado la mayoría de las barreras y se han liberalizado los flujos e intercambios, observamos la enorme paradoja de que por todas partes se pone cerco a la movilidad de las personas (cf. Barry y Goodin 1992). Cuando no se cierran a cal y canto las fronteras, se exigen premiosos y caros visados de entradas o se imponen limitadas cuotas de acceso (vinculadas, por ejemplo, a la posesión de una determinada nacionalidad o de una precisa cualificación profesional). En un mundo en el que, por otro lado, los medios de transporte resultan mucho más rápidos y seguros que en épocas anteriores y que además sus costes son considerablemente más reducidos ( $y$, por tanto, más accesibles para un número mayor de personas), las polí- 
ticas migratorias están regidas de hecho por ordenanzas disuasorias y crecientemente restrictivas para el ingreso y la movilidad de las personas - de ciertas personas, siempre las más vulnerables y con menores recursos- a través de las fronteras internacionales. Es aqui donde este mundo globalizado en tantos aspectos ofrece una de sus caras menos presentables: un mundo fronterizado, reterritorializado incluso, un mundo por el que campan a sus anchas estrategias de vigilancia y control. Y son con frecuencia los propios controles los que, siguiendo una dinámica autopoiética, crean los grupos a controlar.

La actual fase de la globalización está constituida por una serie de procesos de alcance desigual, que configura un mundo selectivamente poroso para los diferentes tipos de intercambios. Se han abierto las fronteras a los mercados, se han reducido las tarifas aduaneras a las mercancías y se han derribado numerosas barreras a la libre circulación de la información y de los capitales, pero no se ha procedido de la misma forma con aquellas otras que interfieren en los desplazamientos de las personas y en su libertad para mudar de lugar de residencia. Asistimos, en suma, a una hipermovilidad, prácticamente sin cortapisas, de los flujos de capital e información en coexistencia con una movilidad restringida para los flujos humanos. No en vano, como sostienen Castles y Miller $(2004,344)$, tales "barreras a la movilidad contradicen las poderosas fuerzas de la globalización que llevan hacia un mayor intercambio económico y cultural". Resulta inquietante tener que admitir que, a este respecto, a muchas personas les iría mucho mejor si se les tratara meramente como mercancías o como meros recursos a disposición de los procesos económicos. La lógica de la economía neoliberal se impone sobre el discurso del control de fronteras. No corre la misma suerte, sin embargo, la lógica de los derechos humanos, que queda postergada.

La libre circulación de personas se ha convertido en un codiciado factor de distinción y estratificación social (cf. Bauman 2001, 8). La alta tasa de movilidad humana, una de las señas distintivas de los tiempos que corren y signo elocuente de la creciente interdependencia de todos los países, tiende de hecho a distribuirse de manera piramidal y asimétrica. En un planeta con tremendas disparidades en ingresos, recursos y oportunidades, no todos pueden permitirse -ni les está permitido- el lujo de ser cosmopolitas; es más, el común de los mortales, la mayoría de quienes habitan el planeta, tienen limitadas severamente sus posibilidades de movimiento. Para otros, sin embargo, el cruce de fronteras únicamente implica una sencilla formalidad. Los Estados emplean de manera diferenciada o selectiva la institución de las fronteras y esta práctica acaba plasmándose en un doble régimen de circulación de los individuos, un hecho quizás mucho más grave que la diferenciación entre circulación de personas y de mercancías (cf. Balibar 2005, 83-84).

La movilidad valiosa es, huelga decirlo, aquella que ha sido elegida y no la realizada bajo coacción de las circunstancias. Sin embargo, esa fortuna no está siempre al alcance de todos. Con la esperanza de cambiar sus opciones en la vida, son muchos los seres humanos que a lo largo de la historia han abandonado el pedazo de tierra que un día les vio nacer y se han asentado en otros lares sobreponiéndose a múltiples dificultades. No son pocos quienes se trasladan únicamente para huir de una situación a todas luces desesperada, provocada por las diferencias de desarrollo o por el desprecio de los derechos básicos. Para muchos, la migración no es más que una opción forzada y no deseada, pues, en realidad, añorarian poder permanecer en el lugar que hasta entonces les había sido habitual y apenas se lamentarian por tener que soportar una cierta inmovilidad. En este sentido, tan básico como el derecho a poder emigrar sería el derecho a no tener que emigrar. También el sesgo sedentario, tan humano o más que el migratorio, ha de ser protegido mediante el reconocimiento del derecho básico a permanecer en el propio país y no ser desplazado de la residencia habitual.

Al comienzo de este artículo se indicó que la posibilidad de moverse por el mundo y de mudar de residencia forma parte esencial de la libertad humana, una "prerrogativa" irrenunciable del ser humano. Aunque esto es difícilmente rebatible, el hecho de abandonar el propio país no es siempre fruto de una decisión voluntaria, sino con frecuencia el resultado de un cúmulo de circunstancias que se imponen al individuo. Afirmar lo contrario supone mantener una ficción de manera inútil y además irresponsable. A lo largo de los siglos, las guerras, los conflictos internos, las persecuciones $y$, en general, la intolerancia han sido factores impulsores de una migración en principio no deseada. Las migraciones también están forzadas por desastres naturales (como, por ejemplo, la desertización o el aumento del nivel de las aguas) y, cada vez más, 
por la degradación medioambiental de raíz antropogénica

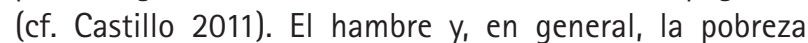
constituyen, no obstante, los principales y más habituales factores de expulsión principales. Con todo, sería inadecuado incurrir en una explicación monocausal $y$, menos aún, en un economicismo reduccionista. Por regla general, sabemos que no son los más pobres quienes emigran, sino quienes tienen los recursos mínimos -no sólo económicospara poder hacerlo. Dicho de manera concisa: no emigra quien quiere, sino quien puede. La cuestión puede ser aún más compleja, pues no siempre la perspectiva del sujeto coincide con la perspectiva del observador: el individuo, como afirma Saskia Sassen (2006, 19), puede entender ciertamente "su propia emigración como el resultado de sus decisiones personales, pero la opción misma de emigrar es un producto social". A este respecto, por tanto, parece bastante sensato mantener una cierta cautela y asumir, como afirma Stefen Castles (2010, 142), que "carecemos de un cuerpo de conocimiento acumulado para explicar por qué algunas personas migran, mientras que la mayoría no lo hacen". Y aunque no cabe, por tanto, aseverar una causa última, puede afirmarse que se precisa la confluencia de otras circunstancias para que la pobreza opere como factor de estímulo de la emigración.

La existencia de antiguos vínculos coloniales y, sobre todo, de redes migratorias transnacionales son, por citar dos ejemplos, variables que facilitan el inicio del proceso migratorio. Lo cierto es que cuando estos factores se desencadenan, ni los muros ni las alambradas de espino logran frenar los flujos migratorios $y$, menos aún, contener los sueños de la gente. Encerrar a los países pobres en su precariedad no resuelve ni alivia el problema de fondo: lejos de aminorarse, las desigualdades y las diferencias de desarrollo se acrecientan. Y además, muy probablemente, todas esas trabas al movimiento de las personas no sirven para alcanzar el objetivo perseguido, pues la inanidad de tantas políticas de firmeza resulta bastante evidente: "la persistencia de la inmigración clandestina, la prosecución del reagrupamiento familiar y el mantenimiento de un colectivo de inmigrantes de gran movilidad sugieren una gran autonomía de los flujos respecto a las políticas disuasivas de control fronterizo" (Wihtol de Wenden 2000, 24).

No deja de ser paradójico que desde que en 1989 se derribara el Muro de Berlín, el emblema de la división geopolítica del planeta, la construcción de nuevos muros y vallas se haya multiplicado (cf. Davis 2008). Ahora, sin embargo, no se trata de mantener separados dos mundos con ideologías enfrentadas. En un intento huero, las barreras se erigen en las fronteras más desiguales del mundo en términos económicos, como la que separa Ceuta y Melilla de Marruecos

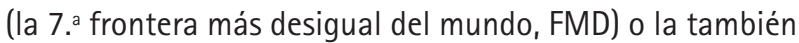
ya mencionada y extensa frontera entre Estados Unidos y México (17. ${ }^{\circ}$ FMD). Su mantenimiento implica apostar por la persistencia de modelos de exclusión y contención que se han demostrado ser tan ineficaces como injustos. En realidad, los muros, los fosos y demás intentos de impermeabilizar las fronteras son ejercicios de demagogia: "se erigen como la solución al problema, cuando sólo pueden contener alguno de los síntomas de la desigualdad, y eso por poco tiempo. Se construyen para ofrecer un símbolo de firmeza al público interno" (Moré 2007, 15).

Si las consideraciones morales no llegan a ser suficientemente persuasivas, en la comprobada ineficacia de las políticas de control puede encontrarse un pragmático argumento a favor de la apertura de fronteras: "Mejor aceptar la inmigración, aunque sea a regañadientes, porque bienvenida o malvenida [...] a ella no hay manera de pararla" (Vargas Llosa 1996). El bloqueo de las fronteras no es ya sólo una tarea policialmente imposible, sino que cada vez resultará más inadmisible tanto en términos sociales como políticos, dado los enormes costes materiales y, sobre todo, humanos que conlleva.

Lo único que de alguna manera puede frenar a los emigrantes sería una mejora sustancial de sus condiciones de vida en sus respectivos países de origen. Si esto es básicamente cierto, entonces no se sostienen opiniones como la expresada por John Rawls $(2001,18)$, quien mantiene que en un mundo globalmente bien ordenado, en un mundo justo, las migraciones constituirían un fenómeno irrelevante, pues sus causas habrian sido eliminadas y, por tanto, no actuarían como elemento de presión sobre la política. En un sentido similar se expresa también Ermanno Vitale (2006, 240), quien afirma que "las migraciones no cesarán si el orden, si así puede llamarse, económico y político mundial no cambia". El desacuerdo no proviene tanto por la literalidad de estas palabras como por lo que parecen sugerir: que en un mundo sin pobreza los movimientos migratorios no tendrian lugar. Sin embargo, esta expectativa no es fácil de satisfacer, pues los desplazamientos y cambios de residencia responden también a algo más profundo y permanente, 
a una suerte de constante antropológica: a una capacidad innata tendente a buscar la mejora de las condiciones de vida. En todo caso, el objetivo, no lo perdamos de vista, no es poner punto final a las migraciones, sino ordenarlas desde principios de justicia. En este sentido, las siguientes palabras resultan sumamente clarificadoras:

\begin{abstract}
"Las teorías de la migración global no deberían estar basadas en el objetivo normativo de encontrar formas de ayudar a la gente a quedarse en sus casas. Más bien, deberían estar basadas en el postulado de que la migración es una parte normal de las relaciones sociales. [...] Si hay un objetivo normativo, éste no debería ser reducir la migración, sino encontrar formas en las que pueda tener lugar bajo condiciones de igualdad y respeto de los derechos humanos" (Castles 2010, 146).
\end{abstract}

\section{Movilidad hUMANA Y JUSTICIA GLOBAL}

Puede fácilmente deducirse cuál es la situación que se deriva del planteamiento recién expuesto. Asistimos a una secuencia perversa de hechos concadenados que tienen como punto de arranque el cuestionamiento generalizado de la libertad de circulación y residencia, un cuestionamiento que conduce al incremento de los controles fronterizos de los flujos de personas y que finalmente conlleva la generación exponencial de irregularidad migratoria. Aunque algunos puedan pensar que esa situación resulta de utilidad para el mantenimiento de un abundante contingente laboral o, en los términos acuñados por Karl Marx en El Capital, de un copioso ejército industrial de reserva, siempre disponible para cubrir las necesidades de la economía (ya sea formal o sumergida) y postergar el escenario del pleno empleo que pudiera poner en riesgo la tasa de beneficios, representa, sobre todo, la perpetuación de una estratificación social que propicia una situación estructural de violación de los derechos humanos muy poco acorde con los presupuestos normativos mínimos de una sociedad bien ordenada. Dicho de otro modo, la política migratoria de numerosos países receptores, inspirada en una filosofía profundamente controladora e incluso criminalizadora de la inmigración no deseada, genera efectos colaterales muy graves en materia de justicia social. Para superar esta situación incompatible con estándares mínimos de equidad y romper con esa espiral endiablada se precisa cambiar de enfoque y adoptar una nueva estrategia. Aunque no sea más que como un esbozo, a continuación se presentarán algunos de los lineamientos básicos de la misma.

Mientras que para incrementar y regular los intercambios económicos se han dado pasos relevantes en las últimas décadas (dotando, por ejemplo, a la Organización Mundial del Comercio de una potente capacidad reguladora), sorprende que nada se haya hecho para gobernar las migraciones internacionales. No es, sin embargo, algo optativo: ante el alcance auténticamente planetario adquirido por los flujos migratorios se impone la necesidad de recuperar una perspectiva global y compleja de los procesos desencadenados por los mismos. La oportunidad e incluso la necesidad de ampliar el punto de vista desde donde examinar las cuestiones sociales en su complejidad y multiplicidad se ha ido abriendo paso paulatinamente entre los cultivadores de las ciencias sociales y la filosofía política y moral (cf. Velasco 2010a). Se ha tomado conciencia de que todos habitamos un solo mundo y que, por tanto, la adopción de una perspectiva meramente estadocéntrica resulta inadecuada para abordar los complejos problemas que se generan en él. Así, si cada Estado busca soluciones por separado a los conflictos y problemas inducidos por las migraciones, éstos encallarán dentro de su reducido marco de actuación (cf. Velasco 2010b). Hace ya tiempo que es difícil dar con un Estado cuyo territorio esté realmente cerrado y ello es así pese al continuo perfeccionamiento de los sistemas de vigilancia de las fronteras. La porosidad de las mismas es una señal más de la progresiva erosión de la soberanía estatal: el nexo político y jurídico entre soberanía y territorio se ha visto cuestionado por la multiplicación de poderes y ordenamientos supranacionales, por el rápido crecimiento e intensificación de los vínculos transnacionales, así como por el afianzamiento de los nuevos circuitos globales de producción y de intercambio de capitales.

En este orden de cosas, el abandono del "nacionalismo metodológico"11 constituiría la condición previa para poder ampliar la escala de análisis y poder apostar así por una concepción global de la justicia apta para un mundo, que es cada vez más el nuestro, en el que los individuos "comparten y son conscientes de compartir, directa o indirectamente, un mismo entorno natural finito" (Arnsperger y Van Parijs 2002, 105). En este contexto, el cosmopolitismo o, por decirlo con Ulrich Beck (2003), una "mirada cosmopolita" aparece como una perspectiva perfilada en ajustada 
respuesta estratégica a las necesidades de análisis de una nueva realidad histórica y social. En un marco global, en donde se hacen presentes cada vez con más fuerza problemas sistémicos de alcance planetario, se requiere que todos los Estados pongan en común recursos, tecnología, servicios de información y también su autoridad, esto es, se precisa una respuesta necesariamente multilateral y coordinada, que haga también posible "reestructurar radicalmente el sistema económico mundial" de acuerdo con las obligaciones de justicia (Beitz 1979, 127). Una redistribución que no puede quedarse en cambios cosméticos ni en apelaciones retóricas, sino que debe afectar al nivel estructural.

Desde esta mirada amplia, de alcance planetario, algunos teóricos de la justicia global se han posicionado a favor de la apertura de las fronteras, que no es lo mismo que un mundo sin fronteras (de hecho, los debates contemporáneos versan más bien sobre la primera que sobre la segunda opción, cf. Wellman 2010). Los argumentos empleados reproducen en gran parte aquellos que habitualmente se proponen a favor de la justicia social o distributiva. Se arguye así que si la igualdad de oportunidades es un principio básico de la justicia, limitar la opción de migrar supone "una discriminación inaceptable en función del lugar de nacimiento o de la ciudadanía" (Arnsperger y Van Parijs 2002, 128). En este mismo sentido, se señala que confinar a los individuos en espacios reducidos y restringuir el acceso a los recursos disponibles en otros países limitan las oportunidades básicas necesarias para llevar una vida digna (cf. Loewe 2007 y 2010). Se incide además en que, consideradas desde la perspectiva de la justicia distributiva, las restricciones de las migraciones hacia los países ricos constituyen una forma ilegítima de intentar respaldar una participación desigual en los finitos recursos del planeta. Si esto es así, entonces convendría desprenderse de tópicos e ideas preconcebidas y no sujetas a contraste empírico como es el caso de la afirmación de que la apertura de fronteras equivale a legitimar una forma de invasión, por muy pacífica que sea, o a alentar una afluencia ingente de migrantes que torne inviable la sostenibilidad de los países receptores $y_{\text {, en }}$ particular, de sus sistemas de protección social. Hay motivos, por el contrario, para pensar que la apertura, al evitar las situaciones de irregularidad, favorece una mejor integración social. La mejora en el respeto de los derechos humanos sería, en todo caso, considerable.
Por otro lado, una eventual apertura de fronteras a los flujos migratorios puede suponer un posible alivio al problema de la pobreza que aqueja a tantos países: no una solución radical, pero sí una respuesta parcial ${ }^{12}$. Dejando aparte la consideración de que la capacidad de decidir dónde se quiere vivir es un elemento básico e innegociable de la libertad de cada ser humano, las migraciones poseen un enorme valor instrumental en cuanto que representan una oportunidad para mejorar el desarrollo no sólo de quienes las protagonizan en propia persona, sino también de los diversos países involucrados, tanto de origen como de destino. Si desde una perspectiva estrictamente económica se asocian razones de eficiencia para justificar la liberalización de los intercambios comerciales, pueden aducirse razones similares también a favor de la movilidad humana $y_{1}$ en particular, de la laboral. De este modo el mundo mejoraría en sus niveles de redistribución y, por tanto, de equidad.

Con la implementación de algún sistema de gobernanza económica global, la libre circulación de personas podria representar un factor impulsor de la redistribución global: "Si estas competencias [de redistribución] se transfirieran a un Estado mundial, la movilidad transnacional podría favorecer la asignación óptima de los factores de producción sin inmunizarlos contra las extracciones fiscales $y_{1}$ desde ese momento, aumentaría sin ambigüedad el potencial de mejora de la suerte de los más desprovistos del planeta" (Arnsperger y Van Parijs, 2002, 130). Aunque el establecimiento de un Estado mundial no es estrictamente necesario y puede ser sustituido ventajosamente por un orden cosmopolita en el que los principales actores fueran instituciones multilaterales y/o alianzas continentales, el alcance del razonamiento de estos dos autores podría ser ampliado y aducirse que una de las formas más sensatas de introducir racionalidad en los flujos migratorios sería precisamente apostar por la regulación del mercado mundial de capitales y por un reparto de la riqueza a nivel planetario menos desigual. De un modo u otro, se trataría de globalizar el bienestar y las oportunidades, de repartir mejor el poder, la riqueza, el acceso a la cultura, las cargas medioambientales, etc. De este modo nos adentraríamos precisamente en donde estriba el quid de la cuestión: "El problema no es la inmigración en sí misma, sino las condiciones de desigualdad bajo las cuales la mayoría de las migraciones norte-sur tienen lugar. Éstas Ilevan a la marginalización y explotación de muchos inmigrantes" (Castles 2010, 145-146).

ARBOR Vol. 188755 mayo-junio [2012] 457-473 ISSN: 0210-1963 
Desde una visión estrictamente chovinista ${ }^{13}$, la restricción del acceso de los extranjeros puede entenderse como un mecanismo legítimo de reservar los recursos de un país en beneficio exclusivo de los propios ciudadanos. En un mundo sin desigualdades tan extremas, esto es, en un mundo en el que todas las sociedades fueran básicamente autosuficientes o, al menos, dispusieran de recursos mínimos, las cosas podrían regularse así, pero lamentablemente no es el caso. $Y$ es a las circunstancias realmente existentes en este mundo a las que ha de adecuarse el proceder de los Estados. En el actual estado de cosas, los Estados están legitimados a seguir manteniendo la facultad de controlar la admisión de extranjeros sólo si satisfacen determinadas condiciones $y$, en concreto, si intervienen mediante alguna suerte de impuesto redistributivo en una participación más justa de los recursos planetarios (cf. Kymlicka 2006, 76-80), esto es, sólo si, en definitiva, contribuyen significativamente y en la medida de sus posibilidades al establecimiento de la justicia global distributiva. En el actual contexto de desigualdad global, los Estados más desarrollados están obligados a contribuir a la redistribución de la riqueza de la Tierra y ello lo pueden hacer básicamente de dos maneras: bien mediante el pago de impuestos, bien mediante la apertura de fronteras. Pueden y deben elegir entre una de esas dos opciones. En uno u otro caso, el objetivo es claro: han de dejar participar a los demás en el reparto del pastel común.

En muchos casos, no todos ciertamente, la transgresión de las fronteras es tan sólo un pequeño síntoma de un mal pandémico llamado pobreza e injusticia global. Difícilmente se puede pretender controlar los movimientos migratorios internacionales sin medidas sustantivas que equilibren la distribución de riqueza y posibiliten la participación igualitaria de todos los países en los beneficios de la globalización. No se puede luchar eficazmente contra una grave enfermedad, y menos aún erradicarla, combatiendo únicamente los síntomas.

\section{UNA CONSIDERACIÓN INTEMPESTIVA: LA UTOPÍA DE LAS FRONTERAS ABIERTAS}

Si durante largo tiempo la cuestión central que estaba en el trasfondo de la reflexión filosófico-política sobre el fenómeno migratorio era el derecho a emigrar, en el presente el punto de controversia gira más bien en torno a los derechos de inmigración y los correspondientes deberes estatales de admitir a extranjeros e incluso a naturalizarlos. A este cambio de enfoque no le es ajeno el reconocimiento del derecho a emigrar como un derecho humano y su consolidación, por tanto, como un derecho protegido. De lo que se trataría ahora es de reconocer el complementario derecho a inmigrar, sin el cual la proclamación del primero no son más que palabras vacías. Es en este terreno de debate donde la apertura de fronteras adquiere su significación más cabal.

Pese a la coherencia interna que pueda tener, una propuesta como la que se ha perfilado en este artículo podría ser rápidamente descalificada de utópica, en el sentido atribuido por el diccionario de la RAE, esto es, como proyecto "que aparece como irrealizable en el momento de su formulación". En el mundo de hoy, un mundo aún cortado al talle de los Estados territoriales soberanos, un mundo que no ha dejado de ser westfaliano (pues, en principio, sigue vigente el principio de no injerencia en los asuntos internos y las fronteras estatales siguen mereciendo la máxima protección internacional), la libre circulación de personas se nos presenta ciertamente como algo para lo que aún no existen las circunstancias requeridas. Pero también es verdad que es una utopía en la línea de aquellas que han hecho mover el mundo: la de un mundo sin esclavos o la de un mundo sin un género subordinado, por poner sólo dos ejemplos. La propuesta aquí formulada puede ser ciertamente utópica, pero no quimérica: no es algo meramente imaginado y que carezca de fundamento alguno. Es más bien una microutopía, una utopía mínima, alejada de toda tentación del macrorrelato social omnicompresivo que no trata de dibujar un mundo perfecto, un paraíso en la tierra, sino que simplemente pretende evitar o al menos mitigar los grandes y constantes males generados por la obsesión de control en la que están atrapados la mayoría de los Estados contemporáneos. Una utopía concentrada fundamentalmente en la prevención de los daños inflingidos por ese afán controlador.

Más allá de sus posibles derivas totalitarias, el valor del pensamiento utópico como potencial motor de transformación social es difícilmente cuestionable ${ }^{14}$. No obstante, la formulación de una utopía será únicamente de utilidad si, además de ser deseable, satisface requisitos mínimos de viabilidad. Son multitud las condiciones materiales que 
han de concurrir a su posible puesta en práctica y que han de ser consideradas. Esta exigencia, por supuesto, también ha de ser tenida en cuenta por el pensar filosófico sobre la materia que nos ocupa: "Dado que a primera vista las restricciones a la libertad de asentamiento parecen injustas (unfair), aunque también inevitables en última instancia, la fundamentación filosófica se ve retada a desarrollar principios que no resulten injustos en el ámbito de las relaciones externas y que, sin embargo, no exijan internamente nada que sea irrealizable" (Somek 1998, 410). Por esta razón, y porque además no se concibe la reflexión planteada como un mero ejercicio de diversión intelectual, sino alentada por una pretensión práctica y por el afán de transformar la realidad social, se ha tratado de ser aquí muy cuidadoso en el dibujo de esa utopía mínima. De ahí que se haya evitado recurrir a la extendida idea de un "mundo sin fronteras" y se haya optado por la noción de "apertura de fronteras", mucho más discreta y accesible. Para esta restricción podrían aducirse diversos argumentos, pero para abreviar se asumirá aquí uno expuesto para defender una propuesta diferente:

\footnotetext{
"De todas formas, dudaria al identificar semejante democracia radical, necesariamente internacionalista (o mejor aún: transnacional), con la persecución de un 'mundo sin fronteras' en el sentido jurídico-político del término. Un 'mundo' de esa índole correría el riesgo de no ser más que el escenario de una dominación salvaje de las potencias privadas que monopolizan el capital, las comunicaciones, acaso el armamento..." (Balibar 2005, 85).
}

La apertura de fronteras representa un nuevo estado de cosas que constituye no sólo un horizonte deseable, sino también una propuesta no menos viable que otras formuladas a lo largo de la historia para responder a conflictos reales irresueltos y que en su momento podrían parecer ilusorias y hoy forman parte de nuestra realidad social. Sin incurrir en angelismo alguno, cabe preguntarse si de hecho no resulta mucho más utópica la opción opuesta propugnada desde posiciones autodesignadas como realistas. $Y$ con esta pregunta no se alude exclusivamente al cierre completo de las fronteras, a la "inmigración cero" tan anhelada por algunos populismos, sino también a la simple pretensión de mantener los flujos migratorios bajo el control de los Estados. Ante las reiteradas inconsistencias que genera la gestión política de estos flujos, la apertura de fronteras se presenta como una opción razonable digna de ser tomada en consideración (cf. Zapata-Barrero 2008). Ya va siendo hora de que se abra en serio el debate público sobre una política de apertura y si el balance costes/beneficios - políticos, económicos y, sobre todo, humanos- que provoca dicha política es más favorable o menos que el balance derivado de una política de contención absoluta de los flujos migratorios.

Los cambios sociales más significativos acaecidos a lo largo de la historia no han sido el resultado de procesos estructurales inexorables, sino fruto de la intervención humana en forma de movilizaciones políticas y luchas sociales. Los límites de lo posible no vienen dados por los límites de lo realmente existente, pues lo real, además de ser contingente, puede ser modificado. Mientras tanto, mantener a la vista una opción situada más allá de lo realmente existente, que no de lo posible, resulta imprescindible para poder someter a una mirada crítica esa perspectiva -cada vez más extendida- que nos presenta la movilidad humana como una potencial amenaza para el orden establecido.

Ese mundo tendencialmente sin fronteras, esa utopía cosmopolita que soñamos, es factible y puede llegar a existir realmente, mas el camino no es recto ni llano y esto tampoco puede ser ocultado. Se requiere encontrar un tipo de soluciones que no sean ni tan endebles que ofendan a la humanidad, ni tan drásticas que desacrediten a los Estados. Dos bienes, la humanidad y el Estado, "que son goznes esenciales de las lógicas políticas modernas" (Galli 2010, 55), aunque introduciendo un relevante matiz. El Estado no es, y menos aún el Estado territorial, un sacrosanto e inviolable hecho natural, sino un producto humano al servicio de las necesidades de los hombres, un mero medio provisto de valor instrumental. Su persistencia, al menos en su actual perfil, dependerá de la capacidad que acredite para responder a los nuevos retos y hacerlo en beneficio de la humanidad entera. 
* Este artículo se ha elaborado en el marco de un proyecto de investigación financiado por el Ministerio de Ciencia e Innovación: "Integración, participación y justicia social" (FFl2009-07056). Agradezco los comentarios y sugerencias recibidos por los participantes del seminario permanente que este proyecto mantiene en el Instituto de Filosofía del CSIC, donde presenté una primera versión. Son muy de agradecer también las valiosas observaciones que Daniel Loewe me transmitió sobre un manuscrito posterior. Por su parte, la Fundación Alexander von Humboldt financió durante el verano de 2011 una estancia en la Technische Universität Berlin que posibilitó el acopio de bibliografía y la redacción final de este trabajo. Una versión preliminar, en formato divulgativo y significativamente abreviada, se publicó en la revista Claves de razón práctica (n. ${ }^{\circ} 219$, enero-febrero 2012).

1 Tanto del derecho a relacionarse como del deber de hospitalidad pueden encontrarse abundantes antecedentes históricos. El denominado ius communicationis ac societatis -el derecho de recorrer otras regiones de la tierra y de establecerse en ellas para asi poder entrar en comunicación con los demás seres humanos- fue introducido en el lenguaje académico por Francisco de Vitoria (en su Relectio de Indis recenter inventis, de 1539). Por su parte, el deber de universal de hospitalidad, así como el correlativo derecho de visita, fue teorizado por Immanuel Kant en su opúsculo sobre La paz perpetua (1795). Por lo demás, la hospitalidad es una extendida e inmemorial costumbre (legendaria es, p.ej., la practicada por los hombres del desierto) prescrita por numerosas tradiciones religiosas, incluida la bíblica (cf. Éxodo 22, 21 y Levítico 19,33).

2 Joseph Carens (1987), por ejemplo, se sirve del conocido experimento mental de John Rawls (la llamada posición original) para responder a esta cuestión: si situados tras un velo de ignorancia, sin conocer el lugar que a cada uno le tocará vivir en este planeta, los representantes de las partes han de llegar a un acuerdo sobre los principios de la justicia, entonces la libertad de movimientos sería reconocida como un derecho universal. Sería, sin duda, el modo más sensato de domesticar el azar y asegurarse de no caer situados en el peor de los escenarios posibles: que a uno le toque nacer en un país sin recursos y carecer además de derechos que le permita acceder a otro.

3 A pesar de lo señalado, el asunto no está exento de discusión. Cabría equiparar el derecho a emigrar, por ejemplo, con el derecho condicional a contraer matrimonio. De este derecho no se deriva, ciertamente, la obligación de nadie a casarse con la persona que invoca tal derecho. Sin embargo, la contraparte del derecho subjetivo a emigrar no son individuos particulares (como en el caso del matrimonio), sino Estados (sujetos de derecho internacional, entre otras cosas) que controlan el acceso a su territorio. Por tanto, la analogía no es ni mucho menos perfecta, pues cuando el Estado garantiza un derecho asume la obligación de poner el ordenamiento jurídico-político al servicio de la pretensión protegida, de modo que ésta sea al menos realizable.

4 Un sentido similar a terra nullius tiene la expresión in vacuis locis, empleada, p.ej., por John Locke (Second Treatise of Government, § 121) para referirse 
a cualquier parte del planeta que supuestamente se encontrase libre y no tuviera dueño, en donde siempre tendría derecho a instalarse quienquiera que no desee someterse a la jurisdicción de un determinado gobierno. Apenas un siglo después, esta posibilidad ya no es contemplada como realista, pues ya se ha tomado clara conciencia de la finitud de nuestro planeta. Así, Kant, al referirse en La paz perpetua (1795) al derecho de visita, lo define como el derecho que posee todo ser humano de "presentarse a la sociedad [...] en virtud del derecho de propiedad en común de la superficie de la tierra, sobre la que los hombres no pueden extenderse hasta el infinito, por ser una superficie esférica, teniendo que soportarse unos junto a otros y no teniendo nadie originariamente más derecho que otro a estar en un determinado lugar de la tierra" (Kant 1985, 27, cursivas de JCV).

5 La implantación de un derecho sancionador ad hoc, cuyo exclusivo destinatario sería el inmigrante desprovisto de los papeles oficiales requeridos (y cuya exprexión más extrema son, sin duda, los Centros de Internamiento de Extranjeros desplegados por toda la Unión Europea), nos situaría en una peligrosa deriva que podría culminar en la creación de un "derecho penal del enemigo" (recurriendo a la famosa categoría de Günther Jakobs, 2006). La retención o detención administrativa sería una extraña figura jurídica en la que encajaría esa deriva. Aunque, por lo demás, esta tendencia coincide con la observada por Étienne Balibar (2008) en sus reflexiones sobre la progresiva identificación del extranjero como enemigo interno, se trata de algo más que una abstracción, pues ya es un hecho comprobable la in- fravaloración legal del inmigrante y el endurecimiento de las normas que regulan su status.

6 La noción de chovinismo del bienestar fue acuñada por Jürgen Habermas hace un par de décadas (1998, 636643) para dar cuenta de la extendida resistencia de las sociedades más desarrolladas a compartir las ventajas y derechos sociales que disfrutan con los migrantes procedentes de los países más atrasados. Con esta noción se designa, en general, las reacciones de carácter defensivo e insolidario desplegadas por las sociedades receptoras ante los procesos migratorios.

7 No se trata de un mero tropo o figura de estilo, sino de un estructurado sistema de control y vigilancia: "La Fortaleza Europa se compone de tres pilares fundamentales: un cerebro panóptico, un sistema común de control de las fronteras y una zona de contención de Estados aliados" (Davis 2008, 256). La base normativa de dicho sistema se asienta sobre el Acuerdo de Schengen en 1985 y el posterior Convenio de Schengen de 1990. Para gestión común de las fronteras externas de la Unión Europea se creó en 2004 la Agencia Europea para la gestión de la cooperación operativa en las fronteras exteriores, conocida por el acrónimo FRONTEX, cuyo presupuesto se ha ido acrecentando desde entonces de manera exponencial.

8 Este argumento puede ser invertido, ciertamente. Se aduce que es precisamente el aumento de inmigrantes lo que conduce a la xenofobia (como si se tratara de una respuesta automática e irrefrenable). Por ello, y para evitar que los conflictos culturales se agraven y terminen por hacer insoportable la vida social, la solución lógica sería entonces el cierre de las fronteras a cal y canto. En todo caso, parece más claro la existencia de un bucle de doble dirección en un tema conexo: "Las relaciones causa-efecto entre securitización y sentimientos hostiles a la inmigración son bidireccionales: la securitización contribuye a la visión negativa de la inmigración y los sentimientos negativos hacia ésta abonan el terreno de la securitización" (Arango 2011, 59).

9 Sin recurrir a la idea de libertad, sino aduciendo meras razones de utilidad pública, desde la época de la llustración comenzó a criticarse como nefasta la prohibición de emigrar. No es ésta, pues, una idea de nuestros días, sino que hace ya casi tres siglos que la encontramos formulada: "Dado que los hombres son excesivos en todo cuanto emprenden y han exagerado esta desigualdad, han implantado en varios países la prohibición a cualquier ciudadano de salir de la comarca donde el azar le ha hecho nacer. Pero el sentido de esta ley es evidente: 'este pais es tan malo y está tan mal gobernado que prohibimos a todos los individuos marcharse de él, temiendo que todo el mundo se vaya'. Sin embargo, hay algo mejor que hacer: proporcionar a todos los súbditos el deseo de permanecer en el país y a los extranjeros el de trasladarse al mismo" (Voltaire 1995, 321-322).

$10 \mathrm{Al}$ menos desde las formulaciones seminales de Jean Bodin y Thomas Hobbes, el vocablo soberanía ha desempeñado un relevante papel en la filosofía política moderna y contemporánea. Presupuesto básico, aunque implícito a veces, es que su ejercicio se ha de dar en régimen de monopolio, esto es, sobre un territorio determinado del que se excluye cualquier otra poder soberano. Desde entonces su

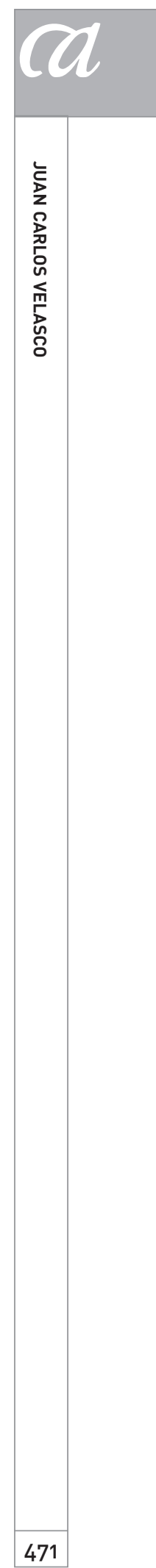


contenido ha ido adquiriendo perfiles diversos e incluso contradictorios, aunque ha sido en los últimos años cuando su sentido ha sido cuestionado de forma más radical (cf. Balibar 2003, 257-284). Si bien existe la tendencia de concebir la soberanía de los Estados como sinónimo de una independencia completa o al menos como la plena capacidad de acción autónoma que disfrutarian los Estados en la esfera interna y externa, en el mundo de nuestros días no cabe duda de que no hay Estado que no depen$d a$ de un modo u otro, de los demás y que, por consiguiente, la soberanía siempre resulta limitada (y ello ya es en sí una contradictio in terminis).

11 Por "nacionalismo metodológico" se entiende aquel extendido enfoque epistémico -una distorsión cognitiva, más bien- que considera a los diferentes Estados nacionales como las unidades básicas para el estudio de los procesos sociales, de modo que todos los análisis se han de ajustar a este marco primario de referencia (cf. Pogge 2005, 181-186; Beck 2005, 38-51).

12 Thomas Pogge (2010), probablemente el más conspicuo adalid de la justicia global, no encuentra, por el contrario, un nexo evidente entre la apertura de fronteras y la lucha contra la pobreza en el mundo. Aunque se muestra partidario de implementar arreglos normativos que mejoren las condiciones de vida de los inmigrantes, sostiene que estas medidas no lograrian solucionar y, menos aún, atajar de raíz la causa principal de las migraciones: la pobreza en el mundo. Arguye que la transferencia internacional de recursos para luchar contra la pobreza global es mucho más eficiente que la acogida de migrantes en los Estados ricos.
13 En realidad, el chovinismo no es más, según el diccionario de la RAE, que la "exaltación desmesurada de lo nacional frente a lo extranjero".

14 Sobre el positivo papel de la utopia, la profunda, erudita y ya clásica obra de Ernst Bloch constituye una referencia de obligada remisión. Esa valoración no es, sin embargo, algo propio del pasado y hoy en día sigue resaltándose su utilidad: "El pensamiento utópico tiene una dimensión inspiradora para buscar soluciones innovadoras frente a problemas, conflictos de unas situaciones históricas particulares. [...] El pensamiento utópico sólo surge cuando hay una falta de orientación real para dar respuesta a interrogantes de nuestra sociedad. [...] Su activación se legitima por la incapacidad del realismo de dar respuestas a dilemas políticos" (Zapata 2008, 29). No puede ocultarse, sin embargo, que, desde una mentalidad conservadora, una utopía también puede ser preconizada como una mera promesa de un futuro mejor que evite tener que ocuparse de transformar el presente.

\section{BIBLIOGRAFÍA}

Anguiano, Maria Eugenia (2010): "Las politicas de control de fronteras en el norte y sur de México", en M. E. Anguiano \& A. M. López Sala (eds.), Migraciones y fronteras, Icaria-CIDOB, 161-183.

Arango, Joaquín (2011): "La 'securitización' de las migraciones internacionales, diez años después", en Vanguardia/ Dossier, n. ${ }^{\circ} 41,54-59$.

Arnsperger, Christian y Van Parijs, Philippe (2002): Ética económica y social, Paidós, Barcelona.

Baggio, Fabio (2010): "Fronteras nacionales, internalizadas y externalizadas", en M. E. Anguiano \& A. M. López Sala (eds.), Migraciones y fronteras, IcariaCIDOB, 49-73.

Balibar, Étienne (2005): Violencias, identidades y civilidad [1997], Gedisa, Barcelona.

- (2003): Nosotros, ¿ciudadanos de Europa? [2001], Tecnos, Madrid.

- (2008): "Del Cosmopolitismo a la Cosmopolítica", en Revista Internacional de Filosofía Política, n. ${ }^{\circ}$ 31, 85-100.

Barry, Brian \& Goodin, Robert E. (1992): Free Movement. Ethical Issues in The Transnational Migration of People and Money, Pennsylvania State U.P., Pennsylvania.

Beck, Ulrich (2005): La mirada cosmopolita o la guerra es la paz, Paidós, Barcelona.

Beitz, Charles S. (1979, 1999²): Political Theory and International Relations, Princeton U.P., Princeton.

Bello, Gabriel (2011): "Emigración e ilegalización: una mirada ética", en Dilemata, n. ${ }^{\circ} 8,83-97$

Benhabib, Seyla (2006): Las reivindicaciones de la cultura [2002], Katz, Buenos Aires.

Carens, Joseph H. (1987): "Aliens and Citizens: The Case for Open Borders", en Review of Politics, 49, 251-273.

- (1992): "Migration and Morality. A Liberal Egalitarian Perspective", en B. Barry \& R. Goodin (eds.): Free Movement, Penn State U.P., Pennsylvania, 25-47.

- (2002): "Inmigración y justicia, ¿a quién dejamos pasar?", en Isegoría, n. ${ }^{\circ} 26$, 5-27.

Castillo, Jesús M. (2011): Migraciones ambientales. Huyendo de la crisis ecológica en el siglo XXI, Virus, Barcelona.

Castles, Stephen (2010): "Comprendiendo la migración global", en Relaciones Internacionales, n. ${ }^{\circ}$ 14, 141-169.

Castles, Stephen y Miller, M. J. (2004): La era de la migración, Universidad Autónoma de Zacatecas/Porrúa, México. 
Celador, Óscar (2011): "Los derechos y libertades de los inmigrantes en el modelo estadounidense. A propósito de la Arizona Inmigration Law SB 1070", en Derechos y libertades, n. ${ }^{\circ} 24,147-$ 177.

Davis, Mike (2008): "El gran muro del capital", en W.AA., 2008, 251-259.

De Genova, Nicholas (2006): "La 'ilegalidad' migratoria y la metafísica del antiterrorismo", en http://www.rebelion. org/noticias/2006/11/41021.pdf

Dummett, Michael (2004): Sobre inmigración y refugiados [2000], Cátedra, Madrid.

Galli, Carlo (2010): La humanidad multicultural, Katz, Buenos Aires/Madrid.

Gingrich, Newt (2010): "La seguridad de nuestras fronteras y la preservación de la civilización norteamericana", en Iglesia viva, n. ${ }^{\circ} 243,77-79$.

Habermas, Jürgen (1998): "Ciudadanía e identidad nacional" [1990], en Facticidad y validez, Trotta, Madrid, 619643.

Hardt, Michael y Negri, Antonio (2002): Imperio [2000], Paidós, Barcelona.

Heller, Agnes (1992): "Diez tesis sobre la inmigración", en El País, edición del 30/05/1992 (http://www.elpais.com/ articulo/opinion/tesis/inmigracion/ elpepiopi/19920530elpepiopi_9/Tes).

Höffe, Otfried (1999): Demokratie im Zeitalter der Globalisierung, Beck, Múnich.

Jakobs, Günther y Cancio, Manuel (2006): Derecho penal del enemigo, Civitas, Madrid.
Kant, Immanuel (1985): La paz perpetua [1795], Tecnos, Madrid.

Kymlicka, Will (2006): Fronteras territoriales [2001], Trotta, Madrid.

Loewe, Daniel (2007): "Inmigración y el derecho de gentes de John Rawls. Argumentos a favor de un derecho a movimiento sin fronteras", en Revista de Ciencia Política, vol. 27, n. ${ }^{\circ}$ 2, 23-48.

- (2010): "Los náufragos de nuestro mundo", en Arbor, n. ${ }^{\circ}$ 744, 555-570.

Mármora, Lelio (2003): Las políticas de migraciones internacionales, Paidós, Buenos Aires.

PNUD (2009): Informe sobre Desarrollo Humano 2009. Superando barreras: movilidad y desarrollo humanos, MundiPrensa, Madrid [acceso online: http:// hdr.undp.org/es/].

Pogge, Thomas (2005): La pobreza en el mundo y los derechos humanos [2002], Paidós, Barcelona.

- (2010): "Migraciones y pobreza" [2005], en Arbor, n. 744, 571-583.

Rawls, John (2001): El derecho de gentes, Paidós, Barcelona.

Sassen, Saskia (2010): Territorio, autoridad y derechos [2006], Katz, Buenos Aires/ Madrid.

Steiner, George (2011): Erratas [1997], Random House Mondadori, Barcelona.

Vargas Llosa, Mario (1996): "Los inmigrantes", en El País, edición del 25/08/1996 (http://www.elpais.com/articulo/ opinion/ESPANA/TERCER_MUNDO/ inmigrantes/elpepiopi/19960825 elpepiopi_4/Tes).
Velasco, Juan Carlos (2009): "Transnacionalismo migratorio y ciudadanía en mutación", en Claves de razón práctica, n. ${ }^{\circ} 197,32-41$.

- (2010a): "El giro globalista de la filosofía de la justicia", en 0. Nudler (ed.), Enciclopedia Iberoamericana de Filosofía vol. 31, Trotta/CSIC, Madrid, 395-422.

- (2010b): "Dejando atrás las fronteras. Las políticas migratorias ante las exigencias de la justicia global", en Arbor n. ${ }^{\circ} 744,585-601$.

Vitale, Ermanno (2006): Ius migrandi, MeIusina, Barcelona.

Voltaire (1985): Diccionario filosófico [1764], Akal, Madrid.

W.AA. (2008): Frontera Sur. Nuevas politicas de gestión y externalización del control de la inmigración en Europa, Virus, Barcelona.

Walzer, Michael (1993): Las esferas de la justicia [1983], FCE, México.

Wellman, Christopher H. (2010): "Immigration", en Edward N. Zalta (ed.), The Stanford Encyclopedia of Philosophy (Summer 2010 Edition), URL = http:// plato.stanford.edu/archives/sum2010/ entries/immigration.

Wihtol de Wenden, Catherine (2000): ¿Hay que abrir las fronteras?, Bellaterra, Barcelona.

Wilcox, Shelley (2009): "The Open Borders Debate on Immigration", en Philosophy Compass, n. ${ }^{\circ} 4 / 5,813-821$.

Zapata-Barrero, Ricard (2008): "Utopia, fronteras y movilidad humana", en $\mathrm{Cla}$ ves de razón práctica, n. ${ }^{\circ} 185,28-36$. 